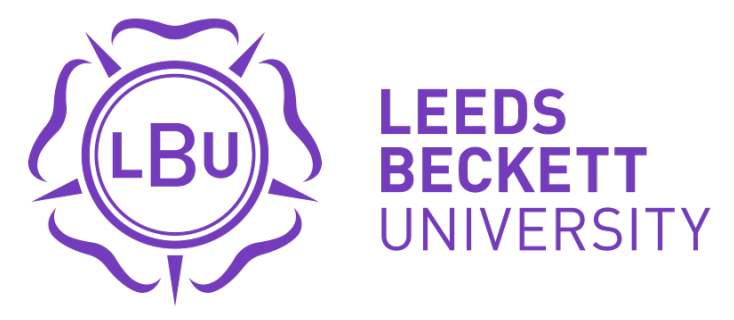

Citation:

Harkness-Armstrong, A and Till, K and Datson, N and Emmonds, S (2020) Technical characteristics of elite youth female soccer match-play: position and age group comparisons between under 14 and under 16 age groups. International Journal of Performance Analysis in Sport. ISSN 2474-8668 DOI: https://doi.org/10.1080/24748668.2020.1820173

Link to Leeds Beckett Repository record:

https://eprints.leedsbeckett.ac.uk/id/eprint/7206/

Document Version:

Article (Accepted Version)

This is an Accepted Manuscript of an article published by Taylor \& Francis in International Journal of Performance Analysis in Sport on 21st September 2020, available online: http://www.tandfonline.com/10.1080/24748668.2020.1820173

The aim of the Leeds Beckett Repository is to provide open access to our research, as required by funder policies and permitted by publishers and copyright law.

The Leeds Beckett repository holds a wide range of publications, each of which has been checked for copyright and the relevant embargo period has been applied by the Research Services team.

We operate on a standard take-down policy. If you are the author or publisher of an output and you would like it removed from the repository, please contact us and we will investigate on a case-by-case basis.

Each thesis in the repository has been cleared where necessary by the author for third party copyright. If you would like a thesis to be removed from the repository or believe there is an issue with copyright, please contact us on openaccess@leedsbeckett.ac.uk and we will investigate on a case-by-case basis. 
Technical characteristics of elite youth female soccer match-play: position and age group comparisons between Under 14 and Under 16 age groups

Alice Harkness-Armstrong*1, Kevin Till ${ }^{1}$, Naomi Datson ${ }^{2}$ and Stacey Emmonds ${ }^{1}$

${ }^{I}$ Institute for Sport, Physical Activity and Leisure, Leeds Beckett University, Leeds, England

${ }^{2}$ Institute of Sport, University of Chichester, Chichester, England

*Corresponding author

Alice Harkness-Armstrong

Carnegie School of Sport

Leeds Beckett University

Cavendish Hall Room 116, Headingley Campus

Leeds, LS6 3QU

United Kingdom

Email: A.Harkness@,leedsbeckett.ac.uk 
Technical characteristics of elite youth female soccer match-play: position and age group comparisons between Under 14 and Under 16 age groups

The purpose of this study was to quantify the technical characteristics of U14 and U16 elite youth female soccer match-play, and compare position-specific differences between and within these age groups. A total of 449 match observations, from 45 matches were undertaken on 189 players (U14 n=81, U16 $\mathrm{n}=108)$ representing Regional Talent Centres $(\mathrm{U} 14 \mathrm{n}=5, \mathrm{U} 16 \mathrm{n}=6)$ in The Football Association's Girls’ England Talent Pathway league. Linear mixed modelling determined position-specific differences for 24 technical and 4 possession-based variables. Results showed similar team possession-based characteristics at both age groups. Interceptions (U14=4.6 $\pm 0.3, \mathrm{U} 16=3.9 \pm 0.3$ ) and tackles (U14=4.2 \pm 0.3 , U16=3.2 \pm 0.3 ) were the most common defensive actions. Passes were the most common offensive action (U14=21.8 \pm 1.8 , $\mathrm{U} 16=25.1 \pm 1.9)$. In possession, U14 central players performed more actions than wide players, whilst actions were more evenly distributed amongst positions at U16, suggesting a variation in playing style between age groups. Technical performances of players were position-dependent, and differences in offensive and defensive variables were observed between age groups across all positions. The findings provide insight into the technical characteristics of elite youth female soccer match-play, which may assist practitioners in informing specific coaching practice, training programme design or talent identification processes within this population.

Keywords: football; match demands; match analysis; performance analysis 


\section{Introduction}

During soccer match-play, players complete unpredictable, highly complex movement patterns that are dependent upon a range of contributing variables (e.g. interaction with the ball, opposition and teammates, or tactical strategies) (Andersson et al., 2008; Mohr et al., 2008). The combination of these physical movements with player technical and tactical actions contribute to match performance (Yi et al., 2018). Understanding match performance is important to enable practitioners to implement evidence-informed practices for player development, optimise performance and increase chance of success, including; training programme design, training load and injury surveillance and talent identification processes (Goto et al., 2015; Rogalski et al., 2013; Woods et al., 2016).

A plethora of studies have quantified the physical and technical characteristics of elite male soccer match-play (Bradley, Lago-Peñas et al., 2013; Bush et al., 2015; Di Salvo et al., 2009). This research has identified that elite male soccer match-play can vary dependent upon situational factors, including; playing position (Bloomfield et al., 2007; Dellal et al., 2010), playing standard (Bradley, Carling et al., 2013; Varley et al., 2017), opposition standard (Lago et al., 2009; Liu et al., 2015) team ranking (Rampinini et al.,2009), and match outcome (Liu et al., 2016; Castellano et al., 2012). However, to date limited research is available for elite female soccer. Of the research available, this has mainly focussed on quantifying the match physical characteristics within senior players (e.g. total distance covered, high-speed running and sprinting; Datson et al., 2017; Datson et al., 2019; Trewin et al., 2018). Recent research has established elite senior female soccer players' physical match performance has increased with the recent growth, development and professionalism of female soccer (Scott et al., 2020). However there is limited understanding of the current technical characteristics of match-play. The disparity of literature regarding technical match performance compared to male players is due to a variety of reasons, including; female soccer leagues and teams not 
having financial resources to utilise data analysis companies (e.g. OPTA). Furthermore, where these data analysis companies have been widely embedded within the male game this has created an accessible data resource for longitudinal, multi-league or multi-team data. The challenges faced in collecting technical match data within elite female soccer populations should be considered, and an appreciation that in order to provide an initial literature base to gain knowledge and insight into technical performance, research may need to be descriptive prior to further exploratory research observed in elite male populations (Bishop, 2008).

The disparity in literature is also apparent within youth populations, as elite youth female soccer research predominantly focuses upon anthropometric and physical characteristics of players (Emmonds, Sawczuk et al., 2018; Emmonds, Till et al., 2018). To date, only three known studies have explored match-play characteristics of elite youth female soccer, which quantify the physical characteristics (Ramos et al., 2017; Ramos et al., 2019; Vescovi, 2014). To our knowledge, no studies have quantified the technical characteristics of elite youth female soccer match-play. This is problematic, given that in England, Regional Talent Clubs (RTCs) were established within an overall aim to develop future senior international players (Emmonds et al., 2017). RTCs are an important component of The FA's Girls England Talent Pathway, with the aim of all youth and senior international players either competing or have competed for an RTC. They provide elite youth female soccer players with an equivalent club structure to men's academies in England. However, data collection practices vary between RTCs, and collecting technical match data is not standard practice. Consequentially, there is limited knowledge and understanding of current matchplay characteristics across the population. This current lack of evidence-base leads to a limited understanding of whether current RTC match-play is appropriately exposing players to match demands required to effectively transition into international youth and/or elite senior soccer environments. Furthermore, a lack of insight into current technical match 
characteristics and how these may differ dependent upon age or playing position, reduces the ability of practitioners to implement specific evidence-informed practice in order to optimally support; the development of players, the transition of players between age groups, and ultimately progression into further elite soccer environments.

Therefore, the aims of this study were to: 1) quantify the technical characteristics of elite youth female soccer match-play for Under 14 (U14) and Under 16 (U16) age groups, 2) compare position-specific technical characteristics between U14 and U16 age groups, and 3) compare position-specific differences within U14 and U16 age groups.

\section{Materials and Methods}

\section{Participants}

A total of 189 youth female soccer players from 5 RTCs at U14 (n=81; age: $12.9 \pm 0.7$ years; height: $158.7 \pm 6.4 \mathrm{~cm}$; body mass: $48.5 \pm 8.9 \mathrm{~kg})$, and 6 RTCs at U16 ( $\mathrm{n}=108$; age: $15.0 \pm 0.6$ years; height: $162.4 \pm 5.9 \mathrm{~cm}$; body mass: $56.1 \pm 6.4 \mathrm{~kg}$ ) age groups participated in the study. Participants were considered elite, as RTCs are the highest standard of domestic youth female soccer in England. Age groups within RTCs are determined by players' chronological age; U14 and U16 are standard competitive age groups. The study received institutional ethical approval, and all players (and parents/guardians) consented to their participation prior to involvement in the study.

\section{Procedures}

There were $321($ mean $=3 \pm 2 ;$ range $=1-8)$ and $283($ mean $=3 \pm 2 ;$ range $=1-7)$ individual player observations were obtained from U14 and U16 age groups, respectively across 45 matches (U14 n=24; U16, $n=21$ ) during the 2018/19 and 2019/20 seasons. All matches were played as part of The Football Association's Girls' England Talent Pathway league. Duration of matches differed between U14 and U16 age groups (35 vs 40-minute halves), and subsequent 
observed match duration was 76:50 ( \pm 05:05 minutes) and 82:58 ( \pm 03:27 minutes), respectively. Additional differences included; pitch dimensions (75m x 45m vs 91m x 56m) and ball size ( $\operatorname{size} 4 v_{s} 5$ ). Matches were played on grass (U14 n=15; U16 n=8) and artificial turf (U14 n=9; U16 n=13), consisted of both home (U14 n=12; U16 n=12) and away (U14 $n=12 ; U 16 n=9$ ) fixtures, and match outcomes included; wins (U14 n=9; U16 n=6), draws (U14 n=7; U16 n=5), and losses (U14 n=8; U16 n=10).

Due to a high number of substitutions (U14 n=6 \pm 3 ; U16 n=6 \pm 3 ), and positional rotations ( $U 14 n=4 \pm 4 ; U 16 n=8 \pm 5$ ) within observed matches, there were limited full-match observations of players playing the same position ( $\mathrm{U} 14 \mathrm{n}=58 \pm 2$; U16 n=59 \pm 3 ). Therefore, to maximise the available dataset, participants were not allocated to playing positions as predominantly observed in the literature; rather, participants' respective playing time at each position contributed to the position's overall match characteristics. Sub-analyses identified no statistically significant differences $(\mathrm{p}<0.05)$ for any technical variable, for all positions in both age groups, between the method adopted in this study $(n=449)$ and full-match observations ( $n=117)$. Thus, a total of $449(\mathrm{U} 14 \mathrm{n}=239$; U16 n=210) positional observations were derived from player observations for analyses, including; central defenders (CD; U14 $n=42 ; \mathrm{U} 16 \mathrm{n}=40$ ), wide defenders (WD; U14 n=48; U16 n=42), central midfielders (CM; U14 n=63; U16 n=59), wide midfielders (WM; U14 n=48; U16 n=42), and forwards (FWD; $\mathrm{U} 14 \mathrm{n}=38 ; \mathrm{U16} \mathrm{n}=27)$.

All matches were recorded by the lead researcher using a video camera (Panasonic HC-V750, Panasonic, Japan) mounted on a tripod, positioned in-line with the centre of the pitch. Following each match, recordings were transferred to a computer, and analysed using a customised coding template (Nacsport Pro Plus, Nacsport, Spain). 24 technical variables and 4 team possession-based variables were selected for analysis. Technical variables were divided into three groups; set-piece, offensive, and defensive. The variables selected for the 
study were reflective of those used within soccer technical analysis literature (Andersson et al., 2008; Yi et al., 2018; Varley et al., 2017; Liu et al., 2013). Operational definitions can be found in Supplementary Material Table 1.

All matches were coded by the lead researcher. To determine intra-operator reliability, one randomly chosen match was analysed twice. Technical variables demonstrated very good levels of intra-operator agreement ( $\kappa=0.98$; O’Donoghue, 2010). One randomly chosen half of a match was coded by another analyst; a staff member within a participating RTC. Overall, the technical variables demonstrated very good levels of inter-operator agreement ( $\kappa=0.98$; O’Donoghue, 2010), with very good level of agreement for; teampossession variables $(\kappa=0.83)$, set-piece variables $(\kappa=0.96)$, defensive variables $(\kappa=0.82)$ and offensive variables $(\kappa=0.84)$.

\section{Statistical analysis}

All statistical analyses were conducted using R (R Core Team, 2019). Using the lme4 package, a generalised linear mixed model was developed to quantify differences in possession and set-piece variables (dependent variable) between age groups (fixed effect), with fixture nested within team as a random effect to account for repeated measures. A second generalised linear mixed model quantified differences in each technical variable (dependent variable), between age groups within playing positions (fixed effects), with fixture as a random effect. To account for repeated measures of observations, fixture was nested within position and team. The assumptions of linearity and normality of distribution of the models were assessed and verified visually, whilst homogeneity of variance was assessed using Levene's Test $(\mathrm{p}>0.05)$. Estimated means for each technical variable were derived from the models using the emmeans package, and reported as mean $( \pm \mathrm{SE})$. Statistical significance was set at $\mathrm{p}<0.05$. Post-hoc comparisons were conducted to identify differences between age groups and positions. Effect size (ES) was also calculated to determine magnitude of the 
difference. ES was classified as trivial $(<0.2)$, small (0.2-0.59), moderate (0.6-1.19), large (1.2-1.99) or very large (>2.0) (Batterham \& Hopkins, 2006). Effects were considered unclear if the $90 \%$ confidence intervals included both substantial $(<0.2)$ positive and negative values (Hopkins et al., 2009).

\section{Results}

\section{Team possession-based variables}

Table 1 shows the mean \pm SE of team possession-based variables. The ball was in play for $58.4 \pm 5.1 \%$ and $59.0 \pm 6.9 \%$ of match-time at U14 and U16, respectively. There were no significant differences nor substantial ESs between age groups for any team possession-based variable.

\section{*** INSERT TABLE 1 NEAR HERE ***}

\section{Set-piece variables}

There were significantly more corners $(10.3 \pm 0.8$ vs $8.0 \pm 0.7$; $\mathrm{p}<0.05$; small ES: $0.25 \pm 0.20)$, and goal-kicks (20.4 \pm 1.0 vs $16.4 \pm 0.9 ; \mathrm{p}<0.01$; small ES: $0.22 \pm 0.12)$ during U14 match-play than U16s. Whilst there were more free-kicks (17.1 \pm 1.6 vs $13.6 \pm 1.2$; small ES: $0.23 \pm 0.21)$, and throw-ins $(69.8 \pm 4.1$ vs $67.7 \pm 4.0$; trivial ES: $0.03 \pm 0.09)$ during U16 match-play.

\section{Offensive variables}

\section{Differences between age groups}

Table 2 shows the estimated mean \pm SE of offensive variables, and the comparison between U14 and U16 age groups. Position-specific differences between age groups show U14 CDs attempted more crosses than U16 CDs, U16 WDs had more offensive touches and dribbles than U14 WDs, and U16 CMs attempted less crosses than U14 CMs. U16 FWDs had a lower 
average duration of possession, attempted more first touch passes, but less dribbles and shots than U14 FWDs.

\section{Differences within age groups}

Figures 1 and 2 show the between-position comparisons within each age group, including ES and statistical significance. No clear differences were observed between positions within either age-group for; successful passes, successful first touch passes or successful dribbles. WDs had greater total duration of possession, average duration of possession, touches per possession, and more offensive touches, dribbles and crosses than CDs, at both age groups. CMs had a lower total and average duration of possessions than WMs, in which they attempted more passes and first touch passes, but less dribbles and crosses than WMs, and U16 WMs had more shots than U16 CMs. When comparing defenders to midfielders; both U14 and U16 defenders had less total number of possessions, total duration of possession, and made less offensive touches than midfielders. CDs had less total and average duration of possession, touches per possession and attempted less dribbles, crosses and shots than midfielders. CDs also made less passes than CMs but more first touch passes than WMs. There was variation in the differences observed between WDs and midfielders between age groups. However, both U14 and U16 WDs, made more crosses than CMs, had a lower average duration of possession, and fewer; touches per possession, dribbles, crosses and shots than WMs. FWDs had a lower number of possessions, attempted fewer passes but more crosses and shots compared to CMs. U14 FWDs attempted less first touch passes but more dribbles with a higher average duration of possessions and greater touches per possession than U14 CMs. Whilst U16 CMs had greater total duration of possessions and offensive touches than U16 FWDs. Compared to WMs, differences with FWDs varied between age groups; U14 WMs attempted more passes and crosses but less shots than FWDs. U16 WMs 
had a greater total and average duration of possession, more touches per possession and offensive touches, and attempted more dribbles and crosses, but U16 FWDs attempted more first touch passes and shots.

\author{
*** INSERT TABLE 2 NEAR HERE *** \\ *** INSERT FIGURE 1 NEAR HERE \\ ***INSERT FIGURE 2 NEAR HERE***
}

\title{
Defensive variables
}

Differences between age groups

Table 3 shows the estimated mean \pm SE of defensive variables, and the comparisons between age groups. U14s made more defensive touches and tackles, but less aerial challenges than U16s. U14 CDs attempted more tackles but less aerial challenges than U16 CDs. U16 WDs made more aerial challenges and clearances than U14 WDs. U14 CMs had more defensive touches and tackles, compared to U16 CMs. U14 WMs and FWDs had more defensive touches, interceptions and tackles than U16 WMs and FWDs, but attempted less aerial challenges.

\section{Differences within age groups}

Figures 3 and 4 show between-position comparisons within each age group, including ES and statistical significance. There were position-specific differences for all defensive variables within each age group. CDs attempted more aerial challenges and fouls but less tackles than WDs at both U14 and U16. Additionally, U14 CDs made more clearances than U14 WDs. The number of defensive touches, clearances, tackles and fouls of CMs were higher than that of WMs at both age groups. Whilst U14 CMs attempted more aerial challenges than U14 
WMs, and U16 CMs made more interceptions than WMs. Comparing defenders to midfielders, defenders in both age groups made more clearances than midfielders, and U16 defenders made more interceptions than U16 midfielders. There were substantial differences in all defensive variables, except blocks, between individual positions for defenders and midfielders within both age groups. When comparing FWDs to midfielders, both U14 and U16 FWDs made less defensive touches, blocks, clearances, interceptions and tackles compared to midfielders.

\author{
*** INSERT TABLE 3 NEAR HERE *** \\ *** INSERT FIGURE 3 NEAR HERE \\ *** INSERT FIGURE 4 NEAR HERE ***
}

\title{
Discussion
}

This study was the first to quantify technical characteristics of elite youth female soccer match-play, and compare position-specific technical characteristics between U14 and U16 age groups. This study utilised one of the largest datasets within research quantifying elite female soccer match characteristics, involving 189 players from six different RTCs. The results showed differences in offensive and defensive technical variables for all positions between age groups. Additionally, match-play technical characteristics are positiondependent, which is consistent with research involving male populations (Sal de RellánGuerra et al., 2019; Dellal et al., 2011; Yi et al., 2018). The performances of FWDs differed the most between age groups, however differences were observed across all positions, which suggests a variation in playing style between age groups. This study contributes to the very limited evidence-base regarding elite youth female soccer match-play, and results can be used to inform population-specific training practices to assist the progression of players within 
elite youth female soccer.

The current study identified that although match durations are greater at U16, there was similar ball in play time due to U16s larger proportion of ball out of play time. The ball in play percentages observed were similar to elite senior female soccer (U14: $58.4 \pm 5.1 \%$; U16: $59.0 \pm 6.9 \%$; vs. senior: $62.0 \pm 7.7 \%$; Datson et al., 2017). There were similar team possession-based characteristics (e.g. duration of possession, passes per possession) at both age groups, with no substantial differences observed. Position-specific possession results show the average team possession involved only two to three individual player possessions at both age groups. When combined with a high number of team possessions, which were short in duration and included a low number of touches and passes per possession, this suggests a high turnover of ball possession and poor ball retention ability at both age groups. Coaches may use the possession-based results from this study to inform coaching practice design to improve individual and team ball retention ability in preparation for matches, and player development.

At U14 and U16, players' total time in possession ranged between 22.0 and $48.0 \mathrm{~s}$, and 30.5 and $56.3 \mathrm{~s}$, respectively. This is notably less than elite female senior soccer $(66.5 \pm 3.4 \mathrm{~s}$; Bradley et al., 2014). Both age groups performed similar touches per possession to elite senior female players (U14: $2.1 \pm 0.1$; U16: $2.1 \pm 0.1$; vs. senior: $2.1 \pm 0.1$; Bradley et al., 2014). These results show an increasing amount of time on the ball during match-play from youth to senior, and coaches may need to prepare players transitioning into the senior game for the increased technical demand experienced during match-play.

Passes were the most frequent offensive action for all U14 and U16 positions. Position-specific comparisons show similar number of passes attempted to elite senior males (U14 range: 17.6-30.8; U16 range: 21.4-31.4; vs. senior male: 22.2-45.8; Bradley, Carling et al., 2013; Bradley, Lago-Peñas et al., 2013). Also, there was a considerably lower successful 
pass percentage than previously observed within elite youth (U14 range: 58.7-67.6\%; U16 range: 56.7-70.3\%; vs. U14-U17 youth male: 73.2-82.7\%; Goto et al., 2019) and senior male match-play (69.3-84.2\%; Bradley, Carling et al., 2013; Bradley, Lago-Peñas et al., 2013; Dellal et al., 2011). A notable proportion of passes were first touch passes at both age groups (U14 range: 30.5-38.6\%; U16 range: 25.9-36.9\%). Yet, observed successful first touch pass percentage was lower than previous elite youth male research (U16: $63.5 \pm 29.3 \%$; U14: $62.0 \pm 31.0 \%$; vs. U17 male: $74.0-80 \%$; Varley et al., 2017). These results suggest a poor passing ability amongst U14 and U16 elite youth female soccer players, which may be contributing to the poor ball retention ability observed at both age groups. Future research should include contextual information for passing, such as length, direction, height, or defensive pressure, to provide further insights into the technical-tactical characteristics within elite youth female soccer match-play.

When considering offensive variables for each position, there were clear differences between U14 and U16 players dependent upon playing position. CDs at both age groups had the least involvement in possession, whilst offensive actions were predominantly passing, with limited direct attacking involvement. CDs also had the least touches per possession, consistent with elite senior male research (Dellal et al., 2011; Andrzejewski et al., 2014). This may be due to CDs being within close proximity to their defensive goal and therefore taking limited touches to receive, control and pass the ball, to reduce the time in which they could be dispossessed.

WDs had more involvement in possession than CDs, attempting more crosses and dribbles at both age groups. U16 WDs had more offensive touches and dribbles, and trivially more passes and crosses than U14 WDs. WMs had the greatest average duration of possession, a high number of offensive touches, and the most crosses and dribbles at both age groups, whilst U16s had trivially more offensive touches, dribbles and crosses than U14s. 
These results suggest wide players have greater involvement in possession at U16s than U14s. This is consistent with male youth research, which identified technical-tactical behaviour differs in small-sided games; with older age groups playing wider than younger players (U17 v U19; Olthof et al., 2015). Coaches should consider how tactical understanding of players may influence technical characteristics within match-play and use this to inform their coaching practice.

CMs play an important offensive role within elite youth female soccer as they attempted the most passes and had the greatest involvement in possession. These results suggest that CMs are important playmakers within offensive play at both age groups, therefore development of CMs passing ability should be an important aspect of player development.

FWDs had notably different offensive technical characteristics at U14 and U16, with U14s having greater average duration of possession and shots, but less passes, first touch passes, and crosses than U16s. These results suggest that U16 FWDs contribute more in possession by passing and creating goal-scoring opportunities through crosses. Whilst U14 FWDs have a goal-scoring role with more emphasis on shooting, but less direct involvement in passing or build-up play. This finding further suggests differences in attacking style between the age groups, which may be influenced by increased technical-tactical understanding at U16s, as previously discussed. Overall the offensive technical characteristics at each age-group shows clear positional profiles in possession, and highlights differences in playing style at each age group. The offensive technical characteristics findings should be used by coaches to inform coaching practice for match-play and player development, and should be considered for talent identification processes.

When considering the defensive variables, interceptions and tackles occurred more than aerial challenges, blocks and clearances. Additionally, similar or more interceptions 
(U14 range: 2.3-6.7; U16 range: 1.6-7.0; vs male: 0.3-6.3; Brito et al., 2017; Liu et al., 2016) and tackles (U14 range: 3.0-5.8; U16 range: 1.9-4.5; vs. male: 0.6-3.4; Bradley, Lago-Peñas et al., 2013; Goto et al., 2019; Liu et al., 2016) were observed at both age groups compared to elite male youth and senior research. This may be consequential of poor passing and ball retention ability as previously discussed, or suggests that elite youth female soccer players have a good ability to dispossess opponents and regain possession. U14 midfielders and FWDs performed a greater number of defensive touches, tackles and interceptions than their U16 counterparts, suggesting U14s may be more effective in regaining possession. However, due to smaller pitch dimensions, U14 players will have less distance to cover to intercept or engage with opponents than U16s. Therefore, closer proximity to opposition may elicit a greater occurrence of defensive actions at U14s. Literature has identified that pitch size impacts defensive technical characteristics within small-sided games, with more tackles and interceptions occurring on smaller pitches (Casamichana \& Castellano 2010; Kelly \& Drust, 2009). Coaches should consider the space used within their coaching practice at each agegroup based on these results.

Central players performed more aerial challenges than wide players at both age groups, which may be expected due to high-balls occurring more in central areas, such as crosses. However, all positions completed more aerial challenges at U16s than U14s, except for CMs. This suggests there may be a variation in playing style between age groups. It is possible that either U16s playing style includes more high-balls and consequently players attempt more aerial challenges, or simply, U16s are more likely to contest for high-balls than U14s. Coaches should consider the increased exposure to aerial challenges when U14 players transition into U16 for coaching practice design, player development and injury risk or monitoring processes. 
Whilst there were some key position-specific differences in defensive variables between age groups, the defensive profile of positions was mostly similar. For example, defenders had the most direct involvement defending with the most touches, clearances and interceptions. Midfielders had less defensive touches, of which defensive actions were predominantly tackling and intercepting. Whilst FWDs had the least direct defensive contribution with only $8.8( \pm 0.8)$ and $6.3( \pm 0.6)$ defensive touches at U14 and U16, respectively. This is consistent with elite male research (Liu et al., 2016), and identifies that defensive technical characteristics are dependent upon playing position. Coaches may use the defensive technical results from this study to help inform position-specific training practice at each age group, and prepare players transitioning between age groups.

The current study provides a novel approach to analysing datasets involving a high number of substitutions, rolling substitutions and positional changes during matches, which result in limited whole match observations. There is currently no standard approach to analysing these datasets. If traditional methods of only using whole-match performances were adopted (Bradley, Lago-Peñas et al., 2013; Sal de Rellán-Guerra et al., 2019; Yi et al., 2018), our sample size would have been reduced by $74 \%$. However, sub-analyses identified no statistically significant differences between the method adopted and only using whole-match performances for any technical variable across all positions at both age groups. Therefore in order to maximise the dataset, using positional observations by contributing respective playing time to each respective position's overall match observation, rather than player observations, presents an alternative approach for technical characteristics analysis. Particular populations where low numbers of whole-match observations present, due to rolling substitutions and frequent positional changes, or populations which have difficulties and barriers to collecting technical match data, such as elite youth female soccer, may benefit from utilising this method to maximise the available dataset for analysis. 
There are some limitations which should be acknowledged. Physical variables should be included alongside technical variables to further understand match characteristics of the population. Future research should explore the influence of situational factors (e.g. score, match outcome, or opposition standard) on match-play within elite youth female soccer. Knowledge of how different situational factors may affect a player's opportunity to perform technical characteristics during match-play, and consequently influence; player development, ability or readiness to transition to youth international or elite senior soccer environments, will provide useful insight for talent identification. Lastly, this study only included on-theball technical characteristics. Future research should aim to quantify off-the-ball technical actions, to provide further insight into the technical characteristics of elite youth female soccer match-play and how this may differ between positions and age groups.

In conclusion, this study is the first to quantify the technical characteristics of elite youth female soccer match-play. Findings identified differences between and within age groups, according to playing positions, which may have implications for coaching session design, player development and talent identification. Coaches should consider how players may have different opportunities to perform technical actions within matches and training. Furthermore, players transitioning between U14 and U16 age groups, may be exposed to varying technical characteristics depending upon their playing position, which may need to be accounted for within coaching practice to address any lack of exposure to specific technical actions during match-play. The findings provide insight into current technical match characteristics of youth female elite soccer, which may assist practitioners in informing agespecific coaching practice, training programme design or talent identification processes, for the progression of players within elite youth female soccer and to support transitions into elite senior environments. 


\section{Disclosure statement}

No potential conflict of interest was reported by the authors.

\section{References}

Andersson, H., Ekblom, B., \& Krustrup, P. (2008). Elite football on artificial turf versus natural grass: movement patterns, technical standards, and player impressions. Journal of Sports Sciences, 26(2), 113-122. https://doi.org/10.1080/02640410701422076

Andrzejewski, M., Chmura, J., \& Pluta, B. (2014). Analysis of motor and technical activities of professional soccer players of the UEFA Europa League. International Journal of Performance Analysis in Sport, 14(2), 504-523.

https://doi.org/10.1080/24748668.2014.11868739

Batterham, A. M., \& Hopkins, W. G. (2006). Making meaningful inferences about magnitudes. International Journal of Sports Physiology and Performance, 1(1), 50-57. https://doi.org/10.1123/ijspp.11.50

Bishop, D. (2008). An applied research model for the sport sciences. Sports Medicine, 38(3), 253-263. https://doi.org/10.2165/00007256-200838030-00005

Bloomfield, J., Polman, R., \& O'Donoghue, P. (2007). Physical demands of different positions in FA Premier League soccer. Journal of Sports Science \& Medicine, 6(1), 63-70.

Bradley, P. S., Carling, C., Diaz, A. G., Hood, P., Barnes, C., Ade, J., ... \& Mohr, M. (2013). Match performance and physical capacity of players in the top three competitive standards of English professional soccer. Human Movement Science, 32(4), 808-821.

https://doi.org/10.1016/j.humov.2013.06.002

Bradley, P. S., Dellal, A., Mohr, M., Castellano, J., \& Wilkie, A. (2014). Gender differences in match performance characteristics of soccer players competing in the UEFA Champions League. Human Movement Science, 33, 159-171.

https://doi.org/10.1016/j.humov.2013.07.024 
Bradley, P. S., Lago-Peñas, C., Rey, E., \& Gomez Diaz, A. (2013). The effect of high and low percentage ball possession on physical and technical profiles in English FA Premier League soccer matches. Journal of Sports Sciences, 31(12), 1261-1270.

https://doi.org/10.1080/02640414.2013.786185

Brito, Â., Roriz, P., Silva, P., Duarte, R., \& Garganta, J. (2017). Effects of pitch surface and playing position on external load activity profiles and technical demands of young soccer players in match play. International Journal of Performance Analysis in Sport, 17(6), 902918. https://doi.org/10.1080/24748668.2017.1407207

Bush, M. D., Archer, D. T., Hogg, R., \& Bradley, P. S. (2015). Factors influencing physical and technical variability in the English Premier League. International Journal of Sports Physiology and Performance, 10(7), 865-872. https://doi.org/10.1123/ijspp2014-0484

Casamichana, D., \& Castellano, J. (2010). Time--motion, heart rate, perceptual and motor behaviour demands in small-sides soccer games: Effects of pitch size. Journal of Sports Sciences, 28(14), 1615-1623. https://doi.org/10.1080/02640414.2010.521168

Castellano, J., Casamichana, D., \& Lago, C. (2012). The use of match statistics that discriminate between successful and unsuccessful soccer teams. Journal of Human Kinetics, 31, 137-147. https://doi.org/10.2478/v10078-012-0015-7

Datson, N., Drust, B., Weston, M., \& Gregson, W. (2019). Repeated high-speed running in elite female soccer players during international competition. Science and Medicine in Football, 3(2), 150-156. https://doi.org/10.1080/24733938.2018.1508880

Datson, N., Drust, B., Weston, M., Jarman, I. H., Lisboa, P. J., \& Gregson, W. (2017). Match physical performance of elite female soccer players during international competition. The Journal of Strength \& Conditioning Research, 31(9), 2379-2387. https://doi.org/10.1519/JSC.0000000000001575

Dellal, A., Chamari, K., Wong, D. P., Ahmaidi, S., Keller, D., Barros, R., ... \& Carling, C. (2011). Comparison of physical and technical performance in European soccer match-play: 
FA Premier League and La Liga. European Journal of Sport Science, 11(1), 51-59. https://doi.org/10.1080/17461391.2010.481334

Dellal, A., Wong, D. P., Moalla, W., \& Chamari, K. (2010). Physical and technical activity of soccer players in the French First League-with special reference to their playing position. International SportMed Journal, 11(2), 278-290.

Di Salvo, V., Gregson, W., Atkinson, G., Tordoff, P., \& Drust, B. (2009). Analysis of high intensity activity in Premier League soccer. International Journal of Sports Medicine, 30(3), 205-212. https://doi.org/10.1055/s-0028-1105950

Emmonds, S., Morris, R., Murray, E., Robinson, C., Turner, L., \& Jones, B. (2017). The influence of age and maturity status on the maximum and explosive strength characteristics of elite youth female soccer players. Science and Medicine in Football, 1(3), 209-215. https://doi.org/10.1080/24733938.2017.1363908

Emmonds, S., Sawczuk, T., Scantlebury, S., Till, K., \& Jones, B. (2018). Seasonal Changes in the Physical Performance of Elite Youth Female Soccer Players. Journal of Strength and Conditioning Research. Advance online publication.

https://doi.org/10.1519/JSC.0000000000002943

Emmonds, S., Till, K., Redgrave, J., Murray, E., Turner, L., Robinson, C., \& Jones, B. (2018). Influence of age on the anthropometric and performance characteristics of high-level youth female soccer players. International Journal of Sports Science \& Coaching, 13(5), 779-786. https://doi.org/10.1177/1747954118757437

Goto, H. (2019). Comparison of match technical performance in the U13 to U18 elite soccer players. Football Science, 16, 1-9.

Goto, H., Morris, J. G., \& Nevill, M. E. (2015). Match analysis of U9 and U10 English premier league academy soccer players using a global positioning system: Relevance for talent identification and development. The Journal of Strength \& Conditioning Research, 29(4), 954-963. https://doi.org/10.1519/JSC.0b013e3182a0d751 
Hopkins, W. G., Marshall, S. W., Batterham, A. M., \& Hanin, J. (2009). Progressive statistics for studies in sports medicine and exercise science. Medicine \& Science in Sports \& Exercise, 4(3), 3-12. https://doi.org/10.1249/MSS.0b013e31818cb278

Kelly, D. M., \& Drust, B. (2009). The effect of pitch dimensions on heart rate responses and technical demands of small-sided soccer games in elite players. Journal of Science and Medicine in Sport, 12(4), 475-479. https://doi.org/10.1016/j.jsams.2008.01.010

Lago, C. (2009). The influence of match location, quality of opposition, and match status on possession strategies in professional association football. Journal of Sports Sciences, 27(13), 1463-1469. https://doi.org/10.1080/02640410903131681

Liu, H., Gómez, M. A., Gonçalves, B., \& Sampaio, J. (2016). Technical performance and match-to-match variation in elite football teams. Journal of Sports Sciences, 34(6), 509-518. https://doi.org/10.1080/02640414.2015.1117121

Liu, H., Gomez, M. Á., Lago-Peñas, C., \& Sampaio, J. (2015). Match statistics related to winning in the group stage of 2014 Brazil FIFA World Cup. Journal of Sports Sciences, 33(12), 1205-1213. https://doi.org/10.1080/02640414.2015.1022578

Liu, H., Yi, Q., Giménez, J. V., Gómez, M. A., \& Lago-Peñas, C. (2015). Performance profiles of football teams in the UEFA Champions League considering situational efficiency. International Journal of Performance Analysis in Sport, 15(1), 371-390.

https://doi.org/10.1080/24748668.2015.11868799

Mohr, M., Krustrup, P., Andersson, H., Kirkendal, D., \& Bangsbo, J. (2008). Match activities of elite women soccer players at different performance levels. The Journal of Strength \& Conditioning Research, 22(2), 341-349. https://doi.org/10.1519/JSC.0b013e318165fef6

O'Donoghue, P. (2010). Measurement issues in performance analysis. In P.O'Donoghue (Ed), Research Methods for Sports Performance Analysis (pp. 149-177). Abingdon, Oxon: Routledge. 
Olthof, S. B., Frencken, W. G., \& Lemmink, K. A. (2015). The older, the wider: On-field tactical behavior of elite-standard youth soccer players in small-sided games. Human Movement Science, 41, 92-102. https://doi.org/10.1016/j.humov.2015.02.004

Ramos, G. P., Nakamura, F. Y., Penna, E. M., Wilke, C. F., Pereira, L. A., Loturco, I., ... \& Coimbra, C. C. (2019). Activity Profiles in U17, U20, and Senior Women's Brazilian National Soccer Teams During International Competitions: Are There Meaningful Differences?. The Journal of Strength \& Conditioning Research, 33(12), 3414-3422. https://doi.org/10.1519/JSC.0000000000002170

Ramos, G. P., Nakamura, F. Y., Pereira, L. A., Junior, W. B., Mahseredjian, F., Wilke, C. F., ... \& Coimbra, C. C. (2017). Movement patterns of a U-20 national women's soccer team during competitive matches: influence of playing position and performance in the first half. International Journal of Sports Medicine, 38(10), 747-754. https://doi.org/10.1055/s-0043110767

R Core Team (2019. R: A language and environment for statistical computing. Vienna, Austria: R Foundation for Statistical Computing.

Rampinini, E., Impellizzeri, F. M., Castagna, C., Coutts, A. J., \& Wisløff, U. (2009). Technical performance during soccer matches of the Italian Serie A league: Effect of fatigue and competitive level. Journal of Science and Medicine in Sport, 12(1), 227-233. https://doi.org/10.1016/j.jsams.2007.10.002

Rogalski, B., Dawson, B., Heasman, J., \& Gabbett, T. J. (2013). Training and game loads and injury risk in elite Australian footballers. Journal of Science and Medicine in Sport, 16(6), 499-503. https://doi.org/10.1016/j.jsams.2012.12.004

Sal de Rellán-Guerra, A., Rey, E., Kalén, A., \& Lago-Peñas, C. (2019). Age-related physical and technical match performance changes in elite soccer players. Scandinavian Journal of Medicine \& Science in Sports, 29(9), 1421-1427. https://doi.org/10.1111/sms.13463

Scott, D., Haigh, J., \& Lovell, R. (2020). Physical characteristics and match performances in women's international versus domestic-level football players: A 2-year, league-wide study. 
Science and Medicine in Football. Advance online publication.

https://doi.org/10.1080/24733938.2020.1745265

Trewin, J., Meylan, C., Varley, M. C., Cronin, J., \& Ling, D. (2018). Effect of match factors on the running performance of elite female soccer players. The Journal of Strength \& Conditioning Research, 32(7), 2002-2009. https://doi.org/10.1519/JSC.0000000000002584

Varley, M. C., Gregson, W., McMillan, K., Bonanno, D., Stafford, K., Modonutti, M., \& Di Salvo, V. (2017). Physical and technical performance of elite youth soccer players during international tournaments: influence of playing position and team success and opponent quality. Science and Medicine in Football, 1(1), 18-29.

https://doi.org/10.1080/02640414.2016.1230676

Vescovi, J. D. (2014). Motion characteristics of youth women soccer matches: Female Athletes in Motion (FAiM) Study. International Journal of Sports Medicine, 35(2), 110-117. https://doi.org/10.1055/s-0033-1345134

Woods, C. T., Joyce, C., \& Robertson, S. (2016). What are talent scouts actually identifying? Investigating the physical and technical skill match activity profiles of drafted and nondrafted U18 Australian footballers. Journal of Science and Medicine in Sport, 19(5), 419-423. https://doi.org/10.1016/j.jsams.2015.04.013

Yi, Q., Jia, H., Liu, H., \& Gómez, M. Á. (2018). Technical demands of different playing positions in the UEFA Champions League. International Journal of Performance Analysis in Sport, 18(6), 926-937. https://doi.org/10.1080/24748668.2018.1528524 
Table 1. Mean \pm SE of team possession-based variables during U14 and U16 elite youth female soccer match-play.

\begin{tabular}{|c|c|c|c|c|c|c|}
\hline & \multicolumn{2}{|c|}{ In Possession } & \multicolumn{2}{|c|}{ Out of Possession } & \multicolumn{2}{|c|}{ Ball Out of Play } \\
\hline & U14 & U16 & U14 & U16 & U14 & U16 \\
\hline $\begin{array}{l}\text { Total Match Time } \\
(\%)\end{array}$ & $\begin{array}{l}29.1 \pm \\
3.9\end{array}$ & $\begin{array}{l}28.3 \pm \\
5.3\end{array}$ & $\begin{array}{l}29.3 \pm \\
4.4\end{array}$ & $\begin{array}{l}30.1 \pm \\
5.5\end{array}$ & $\begin{array}{l}41.6 \pm \\
5.1\end{array}$ & $\begin{array}{l}41.0 \pm \\
6.9\end{array}$ \\
\hline No. of Possessions & $171 \pm 6.0$ & $165 \pm 5.9$ & $170 \pm 6.5$ & $166 \pm 6.3$ & $122 \pm 4.1$ & $121 \pm 4.1$ \\
\hline $\begin{array}{l}\text { Duration of } \\
\text { Possession (s) }\end{array}$ & $8.5 \pm 4.1$ & $8.7 \pm 4.2$ & $8.0 \pm 3.9$ & $9.1 \pm 4.4$ & $\begin{array}{l}15.9 \pm \\
7.6\end{array}$ & $\begin{array}{l}17.0 \pm \\
8.1\end{array}$ \\
\hline $\begin{array}{l}\text { Touches Per } \\
\text { Possession }\end{array}$ & $5.0 \pm 2.4$ & $5.0 \pm 2.4$ & - & - & - & - \\
\hline $\begin{array}{l}\text { Passes Per } \\
\text { Possession }\end{array}$ & $1.5 \pm 0.8$ & $1.6 \pm 0.8$ & - & - & - & - \\
\hline
\end{tabular}


Table 2. Estimated mean \pm SE of offensive variables during U14 and U16 elite youth female soccer match-play estimated from the generalised linear mixed model, and position-specific differences between age groups. ${ }^{*}$ Significant difference between age groups $\left(p<0.05^{*}, p<0.01 * *\right.$, $\left.p<0.001^{* * *}\right)$

\begin{tabular}{|c|c|c|c|c|c|c|c|c|c|c|c|c|c|c|}
\hline & & $\begin{array}{l}\text { No. of } \\
\text { Possessions }\end{array}$ & $\begin{array}{l}\text { Total } \\
\text { Possession } \\
\text { (s) }\end{array}$ & $\begin{array}{l}\text { Average } \\
\text { Possession } \\
\text { (s) }\end{array}$ & $\begin{array}{l}\text { Touches } \\
\text { per } \\
\text { Possession }\end{array}$ & $\begin{array}{l}\text { Offensive } \\
\text { Touch }\end{array}$ & Pass & $\begin{array}{l}\text { Successful } \\
\text { Pass (\%) }\end{array}$ & $\begin{array}{l}\text { First } \\
\text { Touch Pass }\end{array}$ & $\begin{array}{l}\text { Successful } \\
\text { First } \\
\text { Touch Pass } \\
(\%) \\
\end{array}$ & Dribble & $\begin{array}{l}\text { Successful } \\
\text { Dribble } \\
(\%)\end{array}$ & Cross & Shot \\
\hline \multirow[t]{3}{*}{ All } & U14 & $32.2 \pm 2.3$ & $39.4 \pm 6.2$ & $1.12 \pm 0.07$ & $2.08 \pm 0.09$ & $67.7 \pm 6.6$ & $21.8 \pm 1.8$ & $63.3 \pm 31.6$ & $7.4 \pm 0.2$ & $62.0 \pm 31.0$ & $3.9 \pm 0.5$ & $31.2 \pm 15.7$ & $\begin{array}{l}0.8 \pm 0.0 \\
* * *\end{array}$ & $1.0 \pm 0.2$ \\
\hline & U16 & $34.7 \pm 2.3$ & $44.8 \pm 5.7$ & $1.16 \pm 0.07$ & $2.09 \pm 0.08$ & $74.4 \pm 6.8$ & $25.1 \pm 1.9$ & $65.3 \pm 30.2$ & $7.6 \pm 0.3$ & $63.5 \pm 29.3$ & $4.2 \pm 0.5$ & $33.2 \pm 15.4$ & $0.7 \pm 0.0$ & $1.1 \pm 0.2$ \\
\hline & vs & $\begin{array}{l}\text { Trivial ES: } \\
-0.07 \pm 0.16\end{array}$ & $\begin{array}{l}\text { Unclear ES: } \\
-0.28 \pm 0.81\end{array}$ & $\begin{array}{l}\text { Unclear ES: } \\
0.11 \pm 0.51\end{array}$ & $\begin{array}{c}\text { Unclear ES: } \\
-0.04 \pm 0.59\end{array}$ & $\begin{array}{l}\text { Trivial ES: } \\
-0.09 \pm 0.22\end{array}$ & $\begin{array}{l}\text { Trivial ES: } \\
-0.14 \pm 0.18\end{array}$ & $\begin{array}{l}\text { Unclear ES: } \\
-0.03 \pm 1.12\end{array}$ & $\begin{array}{l}\text { Trivial ES: } \\
-0.03 \pm 0.08\end{array}$ & $\begin{array}{l}\text { Unclear ES: } \\
-0.02 \pm 1.12\end{array}$ & $\begin{array}{l}\text { Unclear ES: } \\
-0.07 \pm 0.27\end{array}$ & $\begin{array}{l}\text { Unclear ES: } \\
-0.06 \pm 1.12\end{array}$ & $\begin{array}{l}\text { Trivial ES: } \\
0.16 \pm 0.17\end{array}$ & $\begin{array}{l}\text { Unclear ES: } \\
-0.06 \pm 0.43\end{array}$ \\
\hline \multirow[t]{3}{*}{$\begin{array}{l}\text { Central } \\
\text { Defender }\end{array}$} & U14 & $24.7 \pm 2.1$ & $22.2 \pm 7.2$ & $0.84 \pm 0.10$ & $1.75 \pm 0.12$ & $43.4 \pm 5.0$ & $20.7 \pm 2.0$ & $61.3 \pm 41.0$ & $8.0 \pm 0.6$ & $58.3 \pm 39.1$ & $1.5 \pm 0.3$ & $35.0 \pm 23.7$ & $\begin{array}{l}0.2 \pm 0.0 \\
* * *\end{array}$ & $0.2 \pm 0.1$ \\
\hline & U16 & $27.2 \pm 2.2$ & $30.5 \pm 6.8$ & $0.97 \pm 0.10$ & $1.82 \pm 0.11$ & $51.7 \pm 5.8$ & $24.3 \pm 2.2$ & $69.0 \pm 43.4$ & $8.7 \pm 0.7$ & $67.3 \pm 42.3$ & $1.6 \pm 0.3$ & $26.2 \pm 17.0$ & $0.1 \pm 0.0$ & $0.3 \pm 0.1$ \\
\hline & vs & $\begin{array}{l}\text { Trivial ES: } \\
-0.10 \pm 0.19 \\
\end{array}$ & $\begin{array}{c}\text { Unclear ES: } \\
-0.44 \pm 0.90 \\
\end{array}$ & $\begin{array}{c}\text { Unclear ES: } \\
-0.37 \pm 0.19 \\
\end{array}$ & $\begin{array}{c}\text { Unclear ES: } \\
-0.19 \pm 0.75 \\
\end{array}$ & $\begin{array}{l}\text { Trivial ES: } \\
-0.17 \pm 0.27 \\
\end{array}$ & $\begin{array}{l}\text { Trivial ES: } \\
-0.16 \pm 0.22 \\
\end{array}$ & $\begin{array}{c}\text { Unclear ES: } \\
-0.12 \pm 1.51 \\
\end{array}$ & $\begin{array}{l}\text { Trivial ES: } \\
-0.09 \pm 0.17 \\
\end{array}$ & $\begin{array}{c}\text { Unclear ES: } \\
-0.14 \pm 1.51 \\
\end{array}$ & $\begin{array}{c}\text { Unclear ES: } \\
-0.07 \pm 0.48 \\
\end{array}$ & $\begin{array}{c}\text { Unclear ES: } \\
-0.29 \pm 1.54 \\
\end{array}$ & $\begin{array}{l}\text { Small ES: } \\
0.55 \pm 0.03 \\
\end{array}$ & $\begin{array}{c}\text { Unclear ES: } \\
-0.42 \pm 0.77 \\
\end{array}$ \\
\hline \multirow[t]{3}{*}{$\begin{array}{l}\text { Wide } \\
\text { Defender }\end{array}$} & U14 & $27.3 \pm 2.3$ & $31.5 \pm 7.1$ & $1.07 \pm 0.10$ & $2.05 \pm 0.11$ & $56.3 \pm 6.5$ & $22.3 \pm 2.1$ & $58.7 \pm 39.3$ & $7.6 \pm 0.5$ & $58.4 \pm 39.1$ & $2.8 \pm 0.5$ & $26.8 \pm 18.0$ & $\begin{array}{l}0.8 \pm 0.0 \\
* * *\end{array}$ & $0.2 \pm 0.1$ \\
\hline & U16 & $33.2 \pm 2.7$ & $42.2 \pm 6.8$ & $1.15 \pm 0.10$ & $2.05 \pm 0.11$ & $70.3 \pm 7.8$ & $26.5 \pm 2.4$ & $63.7 \pm 40.1$ & $7.6 \pm 0.6$ & $61.6 \pm 38.7$ & $4.6 \pm 0.8$ & $38.8 \pm 24.4$ & $0.9 \pm 0.0$ & $0.3 \pm 0.1$ \\
\hline & vs & $\begin{array}{l}\text { Trivial ES: } \\
-0.19 \pm 0.19\end{array}$ & $\begin{array}{l}\text { Unclear ES: } \\
-0.56 \pm 0.90\end{array}$ & $\begin{array}{l}\text { Unclear ES: } \\
-0.24 \pm 0.66\end{array}$ & $\begin{array}{c}\text { Unclear ES: } \\
-0.00 \pm 0.74\end{array}$ & $\begin{array}{l}\text { Small ES: } \\
-0.22 \pm 0.26\end{array}$ & $\begin{array}{l}\text { Trivial ES: } \\
-0.17 \pm 0.21\end{array}$ & $\begin{array}{l}\text { Unclear ES: } \\
-0.08 \pm 1.5\end{array}$ & $\begin{array}{l}\text { Trivial ES: } \\
-0.01 \pm 0.17\end{array}$ & $\begin{array}{l}\text { Unclear ES: } \\
-0.05 \pm 0.42\end{array}$ & $\begin{array}{l}\text { Small ES: } \\
-0.47 \pm 0.42\end{array}$ & $\begin{array}{l}\text { Unclear ES: } \\
-0.37 \pm 1.51\end{array}$ & $\begin{array}{l}\text { Trivial ES: } \\
-0.15 \pm 0.01\end{array}$ & $\begin{array}{l}\text { Unclear ES: } \\
-0.48 \pm 0.76\end{array}$ \\
\hline \multirow[t]{3}{*}{$\begin{array}{l}\text { Central } \\
\text { Midfielder }\end{array}$} & U14 & $42.5 \pm 3.5$ & $47.8 \pm 7.1$ & $1.09 \pm 0.10$ & $2.10 \pm 0.11$ & $90.6 \pm 10.4$ & $30.8 \pm 2.8$ & $61.8 \pm 41.4$ & $9.4 \pm 0.6$ & $56.1 \pm 37.6$ & $5.8 \pm 0.9$ & $30.8 \pm 21.1$ & $\begin{array}{l}0.8 \pm 0.0 \\
* * *\end{array}$ & $2.1 \pm 0.4$ \\
\hline & U16 & $43.1 \pm 3.4$ & $54.3 \pm 6.6$ & $1.19 \pm 0.09$ & $2.16 \pm 0.11$ & $95.6 \pm 10.5$ & $31.4 \pm 2.8$ & $70.3 \pm 44.2$ & $8.4 \pm 0.6$ & $61.1 \pm 38.7$ & $4.4 \pm 0.8$ & $40.2 \pm 25.3$ & $0.4 \pm 0.0$ & $1.9 \pm 0.4$ \\
\hline & vs & $\begin{array}{l}\text { Trivial ES: } \\
-0.01 \pm 0.17 \\
\end{array}$ & $\begin{array}{c}\text { Unclear ES: } \\
-0.34 \pm 0.89 \\
\end{array}$ & $\begin{array}{l}\text { Unclear ES: } \\
-0.28 \pm 0.65 \\
\end{array}$ & $\begin{array}{l}\text { Unclear ES: } \\
-0.16 \pm 0.73 \\
\end{array}$ & $\begin{array}{l}\text { Unclear ES: } \\
-0.05 \pm 0.26 \\
\end{array}$ & $\begin{array}{l}\text { Trivial ES: } \\
-0.02 \pm 0.21 \\
\end{array}$ & $\begin{array}{c}\text { Unclear ES: } \\
-0.13 \pm 1.51 \\
\end{array}$ & $\begin{array}{l}\text { Trivial ES: } \\
0.12 \pm 0.15 \\
\end{array}$ & $\begin{array}{l}\text { Unclear ES: } \\
-0.09 \pm 1.51 \\
\end{array}$ & $\begin{array}{l}\text { Unclear ES: } \\
0.08 \pm 0.41 \\
\end{array}$ & $\begin{array}{l}\text { Unclear ES: } \\
-0.27 \pm 1.53 \\
\end{array}$ & $\begin{array}{l}\text { Small ES: } \\
0.59 \pm 0.03 \\
\end{array}$ & $\begin{array}{c}\text { Unclear ES: } \\
-0.08 \pm 0.46 \\
\end{array}$ \\
\hline \multirow[t]{3}{*}{$\begin{array}{l}\text { Wide } \\
\text { Midfielder }\end{array}$} & U14 & $35.9 \pm 3.0$ & $48.0 \pm 7.1$ & $1.30 \pm 0.10$ & $2.23 \pm 0.11$ & $83.6 \pm 9.6$ & $19.8 \pm 1.9$ & $67.5 \pm 45.2$ & $6.3 \pm 0.5$ & $65.7 \pm 44.0$ & $7.2 \pm 1.2$ & $30.1 \pm 20.2$ & $\begin{array}{l}2.4 \pm 0.0 \\
* * *\end{array}$ & $2.3 \pm 0.5$ \\
\hline & U16 & $38.8 \pm 3.1$ & $56.3 \pm 6.8$ & $1.36 \pm 0.10$ & $2.31 \pm 0.11$ & $91.1 \pm 10.0$ & $22.8 \pm 2.1$ & $56.7 \pm 35.6$ & $5.9 \pm 0.5$ & $56.6 \pm 35.6$ & $8.1 \pm 1.4$ & $33.3 \pm 20.9$ & $2.7 \pm 0.0$ & $2.3 \pm 0.5$ \\
\hline & vs & $\begin{array}{l}\text { Trivial ES: } \\
-0.08 \pm 0.19\end{array}$ & $\begin{array}{l}\text { Unclear ES: } \\
-0.37 \pm 0.92\end{array}$ & $\begin{array}{l}\text { Unclear ES: } \\
-0.17 \pm 0.67\end{array}$ & $\begin{array}{c}\text { Unclear ES: } \\
-0.21 \pm 0.74\end{array}$ & $\begin{array}{l}\text { Trivial ES: } \\
-0.09 \pm 0.26\end{array}$ & $\begin{array}{l}\text { Trivial ES: } \\
-0.14 \pm 0.22\end{array}$ & $\begin{array}{l}\text { Unclear ES: } \\
0.17 \pm 1.52\end{array}$ & $\begin{array}{l}\text { Trivial ES: } \\
0.06 \pm 0.18\end{array}$ & $\begin{array}{l}\text { Unclear ES: } \\
0.15 \pm 1.5\end{array}$ & $\begin{array}{l}\text { Unclear ES: } \\
-0.11 \pm 0.40\end{array}$ & $\begin{array}{l}\text { Unclear ES: } \\
-0.10 \pm 1.51\end{array}$ & $\begin{array}{l}\text { Trivial ES: } \\
-0.13 \pm 0.01\end{array}$ & $\begin{array}{l}\text { Unclear ES: } \\
-0.02 \pm 0.47\end{array}$ \\
\hline \multirow[t]{3}{*}{ Forward } & U14 & $33.7 \pm 2.8$ & $47.6 \pm 7.2$ & $1.30 \pm 0.10$ & $2.26 \pm 0.12$ & $77.1 \pm 8.9$ & $17.6 \pm 1.7$ & $67.6 \pm 45.3$ & $6.4 \pm 0.5$ & $72.9 \pm 48.8$ & $6.3 \pm 1.1$ & $34.2 \pm 22.9$ & $\begin{array}{l}1.2 \pm 0.0 \\
* * * \\
\end{array}$ & $4.8 \pm 0.9$ \\
\hline & U16 & $33.2 \pm 2.8$ & $40.6 \pm 7.1$ & $1.11 \pm 0.10$ & $2.13 \pm 0.12$ & $72.0 \pm 8.0$ & $21.4 \pm 2.0$ & $67.8 \pm 42.6$ & $7.9 \pm 0.7$ & $72.0 \pm 45.3$ & $5.0 \pm 0.9$ & $29.9 \pm 18.9$ & $1.3 \pm 0.0$ & $2.8 \pm 0.6$ \\
\hline & vs & $\begin{array}{l}\text { Trivial ES: } \\
0.01 \pm 0.19\end{array}$ & $\begin{array}{l}\text { Unclear ES: } \\
0.37 \pm 0.92\end{array}$ & $\begin{array}{l}\text { Small ES: } \\
0.51 \pm 0.70\end{array}$ & $\begin{array}{l}\text { Unclear ES: } \\
0.37 \pm 0.78\end{array}$ & $\begin{array}{l}\text { Trivial ES: } \\
0.07 \pm 0.26\end{array}$ & $\begin{array}{l}\text { Trivial ES: } \\
-0.19 \pm 0.22\end{array}$ & $\begin{array}{l}\text { Unclear ES: } \\
-0.00 \pm 1.51\end{array}$ & $\begin{array}{l}\text { Small ES: } \\
-0.22 \pm 0.20\end{array}$ & $\begin{array}{l}\text { Unclear ES: } \\
0.01 \pm 1.51\end{array}$ & $\begin{array}{l}\text { Small ES: } \\
0.24 \pm 0.42\end{array}$ & $\begin{array}{l}\text { Unclear ES: } \\
0.13 \pm 1.52\end{array}$ & $\begin{array}{l}\text { Trivial ES: } \\
-0.04 \pm 0.00\end{array}$ & $\begin{array}{l}\text { Small ES: } \\
0.53 \pm 0.47\end{array}$ \\
\hline
\end{tabular}


Table 3. Estimated mean \pm SE of defensive variables during U14 and U16 elite youth female soccer match-play estimated from the generalised linear mixed model, and position-specific differences between age groups. *Significant difference between age groups $\left(p<0.05^{*}, p<0.01 * *\right.$, $p<0.001 * * *)$

\begin{tabular}{|c|c|c|c|c|c|c|c|c|}
\hline & & Defensive Touch & Aerial Challenge & Block & Clearance & Interception & Tackle & Foul \\
\hline \multirow[t]{3}{*}{ All } & U14 & $16.9 \pm 1.0 *$ & $1.7 \pm 0.2 * * *$ & $1.4 \pm 0.2$ & $0.7 \pm 0.2$ & $4.6 \pm 0.3$ & $4.2 \pm 0.3 *$ & $0.5 \pm 0.1$ \\
\hline & U16 & $13.9 \pm 0.8$ & $2.6 \pm 0.2$ & $1.3 \pm 0.2$ & $0.9 \pm 0.3$ & $3.9 \pm 0.3$ & $3.2 \pm 0.3$ & $0.5 \pm 0.1$ \\
\hline & vs. & $\begin{array}{l}\text { Trivial ES: } \\
0.19 \pm 0.14\end{array}$ & $\begin{array}{l}\text { Small ES: } \\
-0.47 \pm 0.22\end{array}$ & $\begin{array}{l}\text { Unclear ES: } \\
0.05 \pm 0.30\end{array}$ & $\begin{array}{l}\text { Unclear ES: } \\
-0.21 \pm 0.56\end{array}$ & $\begin{array}{l}\text { Trivial ES: } \\
0.17 \pm 0.15\end{array}$ & $\begin{array}{l}\text { Small ES: } \\
0.28 \pm 0.18\end{array}$ & $\begin{array}{l}\text { Unclear ES: } \\
-0.10 \pm 0.39\end{array}$ \\
\hline \multirow{3}{*}{$\begin{array}{l}\text { Central } \\
\text { Defender }\end{array}$} & U14 & $21.9 \pm 1.7$ & $1.8 \pm 0.3 *$ & $1.3 \pm 0.3$ & $3.8 \pm 0.9$ & $6.7 \pm 0.7$ & $3.8 \pm 0.4$ & $0.5 \pm 0.1$ \\
\hline & U16 & $19.2 \pm 1.5$ & $3.5 \pm 0.5$ & $1.5 \pm 0.3$ & $4.1 \pm 0.9$ & $6.2 \pm 0.7$ & $2.9 \pm 0.4$ & $0.5 \pm 0.1$ \\
\hline & vs. & $\begin{array}{l}\text { Trivial ES: } \\
0.13 \pm 0.18 \\
\end{array}$ & $\begin{array}{l}\text { Moderate ES: } \\
-0.69 \pm 0.35 \\
\end{array}$ & $\begin{array}{l}\text { Unclear ES: } \\
-0.15 \pm 0.45 \\
\end{array}$ & $\begin{array}{l}\text { Unclear ES: } \\
-0.08 \pm 0.53 \\
\end{array}$ & $\begin{array}{l}\text { Trivial ES: } \\
0.07 \pm 0.26 \\
\end{array}$ & $\begin{array}{l}\text { Small ES: } \\
0.27 \pm 0.27 \\
\end{array}$ & $\begin{array}{l}\text { Unclear ES: } \\
-0.00 \pm 0.62 \\
\end{array}$ \\
\hline \multirow{3}{*}{$\begin{array}{l}\text { Wide } \\
\text { Defender }\end{array}$} & U14 & $20.6 \pm 1.6$ & $1.3 \pm 0.2 *$ & $1.1 \pm 0.2$ & $1.5 \pm 0.4$ & $6.6 \pm 0.7$ & $4.6 \pm 0.5$ & $0.2 \pm 0.1$ \\
\hline & U16 & $21.5 \pm 1.7$ & $2.5 \pm 0.4$ & $1.4 \pm 0.3$ & $3.6 \pm 0.8$ & $7.0 \pm 0.8$ & $4.5 \pm 0.5$ & $0.3 \pm 0.1$ \\
\hline & vs. & $\begin{array}{l}\text { Trivial ES: } \\
-0.04 \pm 0.18 \\
\end{array}$ & $\begin{array}{l}\text { Moderate ES: } \\
-0.71 \pm 0.36 \\
\end{array}$ & $\begin{array}{l}\text { Unclear ES: } \\
-0.22 \pm 0.45 \\
\end{array}$ & $\begin{array}{l}\text { Moderate ES: } \\
-0.88 \pm 0.55\end{array}$ & $\begin{array}{l}\text { Trivial ES: } \\
-0.05 \pm 0.25 \\
\end{array}$ & $\begin{array}{l}\text { Unclear ES: } \\
0.04 \pm 0.25\end{array}$ & $\begin{array}{l}\text { Unclear ES: } \\
-0.48 \pm 0.75 \\
\end{array}$ \\
\hline \multirow{3}{*}{$\begin{array}{l}\text { Central } \\
\text { Midfielder }\end{array}$} & U14 & $21.0 \pm 1.6$ & $2.5 \pm 0.3$ & $1.6 \pm 0.3$ & $0.9 \pm 0.2$ & $4.9 \pm 0.5$ & $5.8 \pm 0.6$ & $0.7 \pm 0.2$ \\
\hline & U16 & $16.8 \pm 1.3$ & $2.8 \pm 0.4$ & $1.3 \pm 0.2$ & $1.1 \pm 0.3$ & $4.2 \pm 0.5$ & $4.5 \pm 0.5$ & $0.8 \pm 0.2$ \\
\hline & vs. & $\begin{array}{l}\text { Small ES: } \\
0.22 \pm 0.18\end{array}$ & $\begin{array}{l}\text { Unclear ES: } \\
-0.11 \pm 0.32\end{array}$ & $\begin{array}{l}\text { Unclear ES: } \\
0.21 \pm 0.42\end{array}$ & $\begin{array}{l}\text { Unclear ES: } \\
-0.29 \pm 0.57\end{array}$ & $\begin{array}{l}\text { Trivial ES: } \\
0.15 \pm 0.26\end{array}$ & $\begin{array}{l}\text { Small ES: } \\
0.25 \pm 0.23\end{array}$ & $\begin{array}{l}\text { Unclear ES: } \\
-0.13 \pm 0.52\end{array}$ \\
\hline \multirow{3}{*}{$\begin{array}{l}\text { Wide } \\
\text { Midfielder }\end{array}$} & U14 & $16.6 \pm 1.3$ & $2.0 \pm 0.3$ & $1.6 \pm 0.3$ & $0.5 \pm 0.1$ & $4.1 \pm 0.5$ & $4.2 \pm 0.5$ & $0.5 \pm 0.1$ \\
\hline & U16 & $12.0 \pm 1.0$ & $2.5 \pm 0.4$ & $1.4 \pm 0.3$ & $0.5 \pm 0.2$ & $2.9 \pm 0.4$ & $2.9 \pm 0.3$ & $0.5 \pm 0.1$ \\
\hline & vs. & $\begin{array}{l}\text { Small ES: } \\
0.32 \pm 0.19 \\
\end{array}$ & $\begin{array}{l}\text { Small ES: } \\
-0.22 \pm 0.34 \\
\end{array}$ & $\begin{array}{l}\text { Unclear ES: } \\
0.11 \pm 0.44 \\
\end{array}$ & $\begin{array}{l}\text { Unclear ES: } \\
-0.10 \pm 0.67 \\
\end{array}$ & $\begin{array}{l}\text { Small ES: } \\
0.35 \pm 0.28 \\
\end{array}$ & $\begin{array}{l}\text { Small ES: } \\
0.38 \pm 0.26 \\
\end{array}$ & $\begin{array}{l}\text { Unclear ES: } \\
0.10 \pm 0.61 \\
\end{array}$ \\
\hline \multirow[t]{3}{*}{ Forward } & U14 & $8.8 \pm 0.8$ & $1.1 \pm 0.2$ & $1.2 \pm 0.3$ & $0.1 \pm 0.0$ & $2.3 \pm 0.3$ & $3.0 \pm 0.4$ & $0.4 \pm 0.1$ \\
\hline & U16 & $6.3 \pm 0.6$ & $2.1 \pm 0.4$ & $0.9 \pm 0.2$ & $0.1 \pm 0.0$ & $1.6 \pm 0.3$ & $1.9 \pm 0.3$ & $0.4 \pm 0.1$ \\
\hline & vs. & $\begin{array}{l}\text { Small ES: } \\
0.34 \pm 0.23\end{array}$ & $\begin{array}{l}\text { Moderate ES: } \\
-0.63 \pm 0.41\end{array}$ & $\begin{array}{l}\text { Unclear ES: } \\
0.31 \pm 0.52\end{array}$ & $\begin{array}{l}\text { Unclear ES: } \\
0.28 \pm 1.45\end{array}$ & $\begin{array}{l}\text { Small ES: } \\
0.35 \pm 0.36\end{array}$ & $\begin{array}{l}\text { Small ES: } \\
0.46 \pm 0.33\end{array}$ & $\begin{array}{l}\text { Unclear ES: } \\
0.00 \pm 0.70\end{array}$ \\
\hline
\end{tabular}




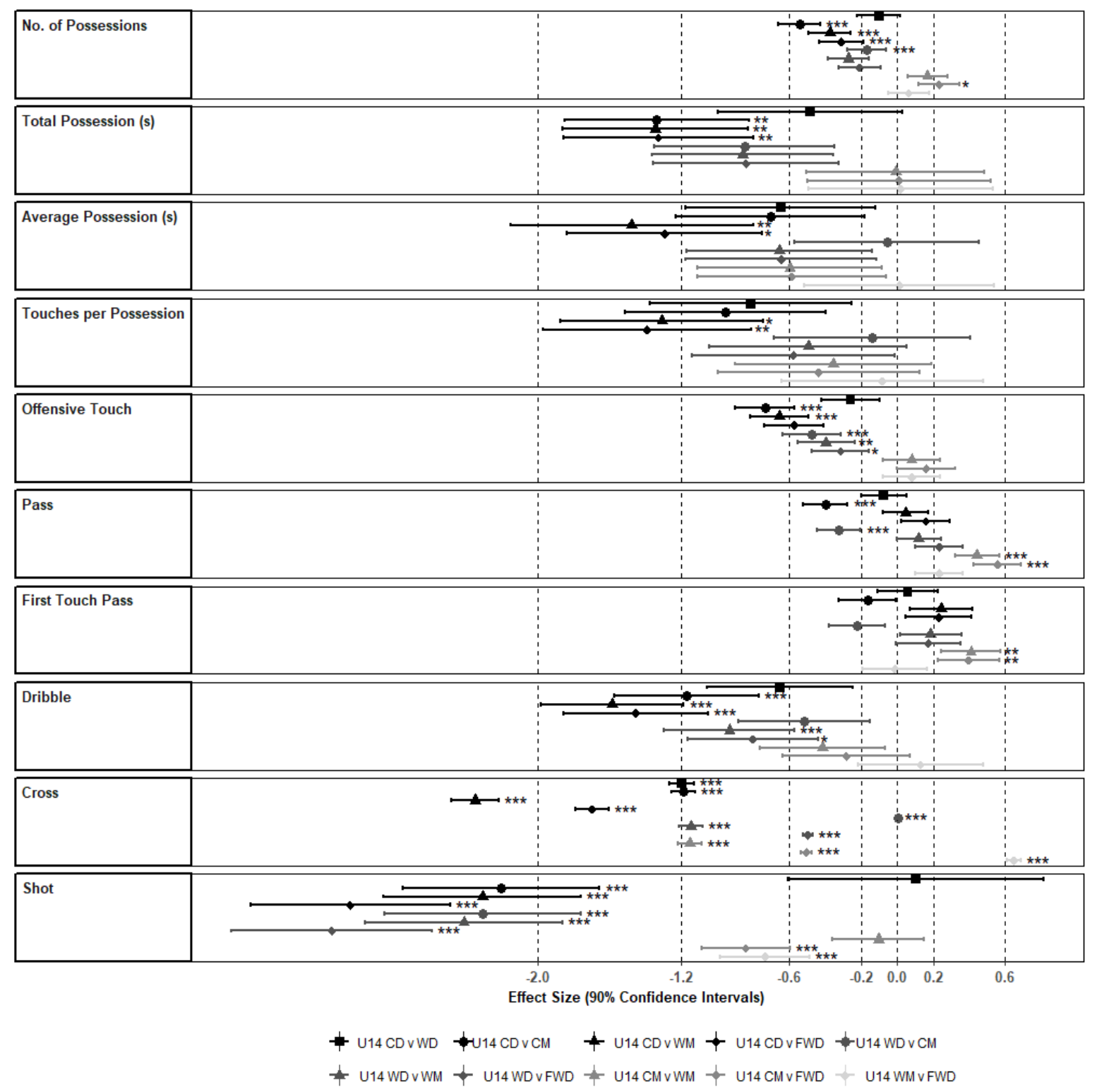

Figure 1. Effect sizes of differences in estimated mean and statistical significance of offensive variables between U14 players by position. *Significant difference ( $p<0.05^{*}$, $\left.p<0.01^{* *}, p<0.001^{* * *}\right)$ 


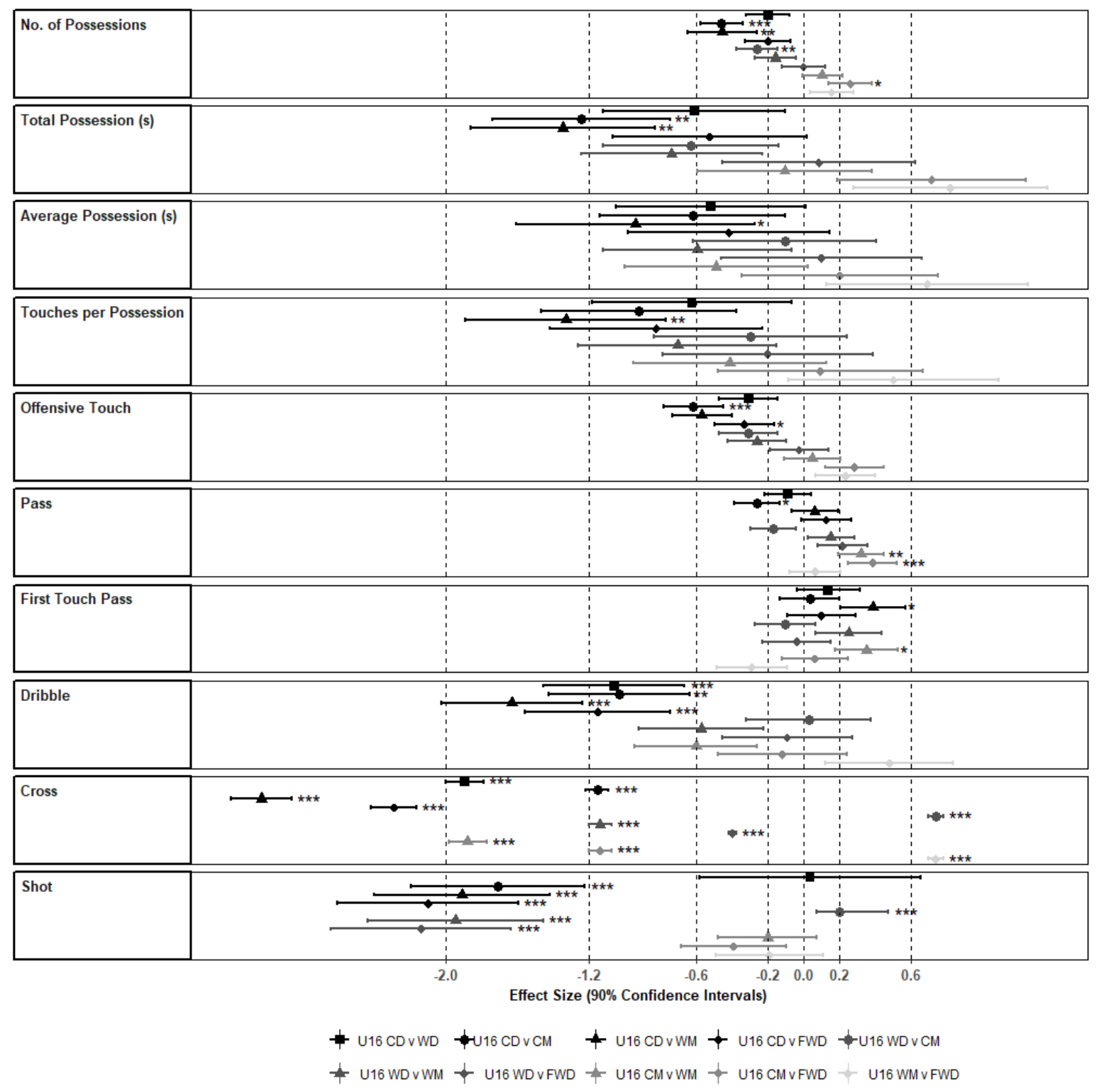

Figure 2. Effect sizes of differences in estimated mean and statistical significance of offensive variables between U16 players by position. *Significant difference $\left(p<0.05^{*}\right.$, $\left.p<0.01^{* *}, p<0.001^{* * *}\right)$ 


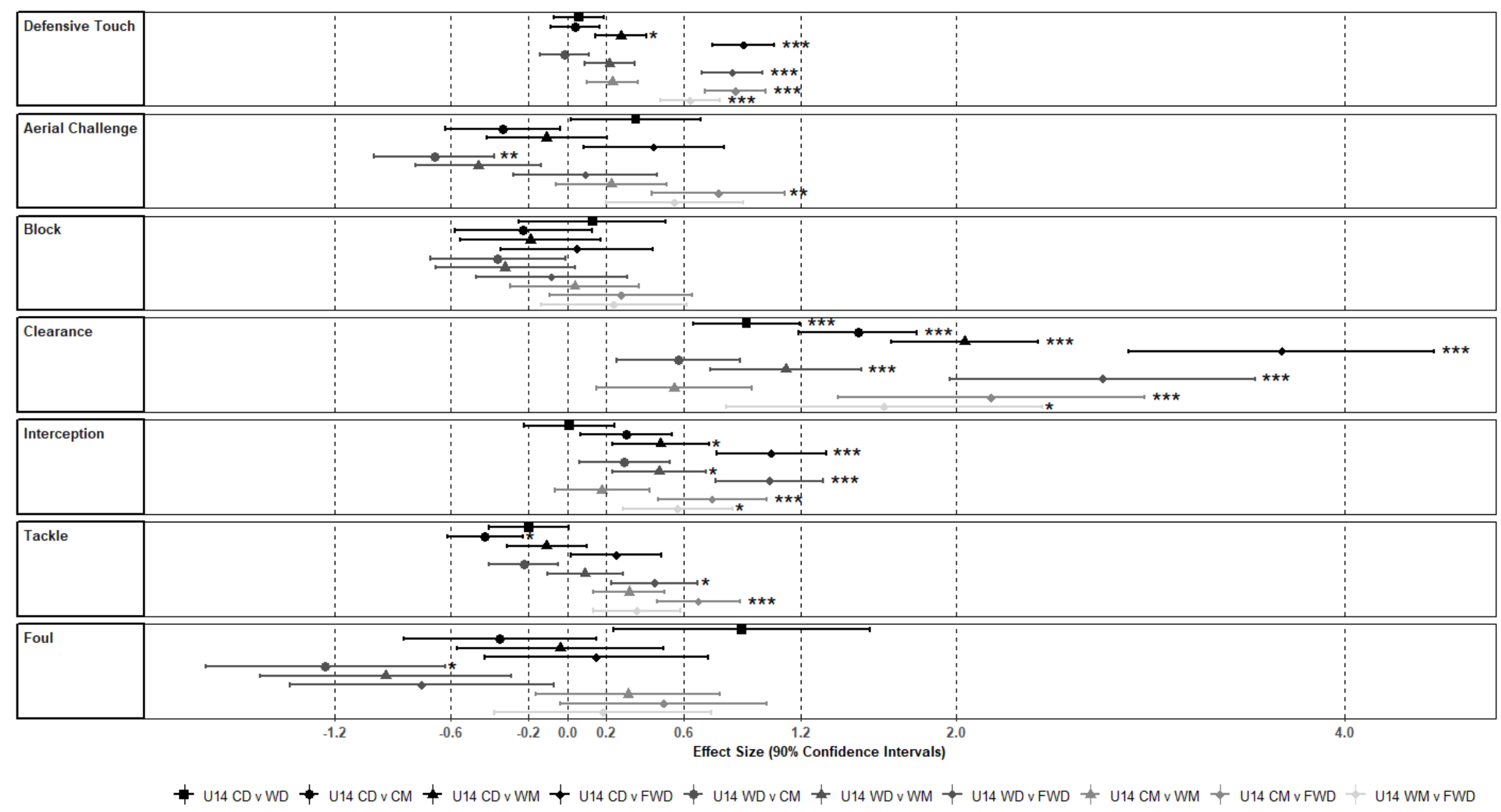

Figure 3. Effect sizes of differences in estimated mean and statistical significance of defensive variables between U14 players by position. *Significant difference $\left(p<0.05^{*}, p<0.01 * *, p<0.001 * * *\right)$ 


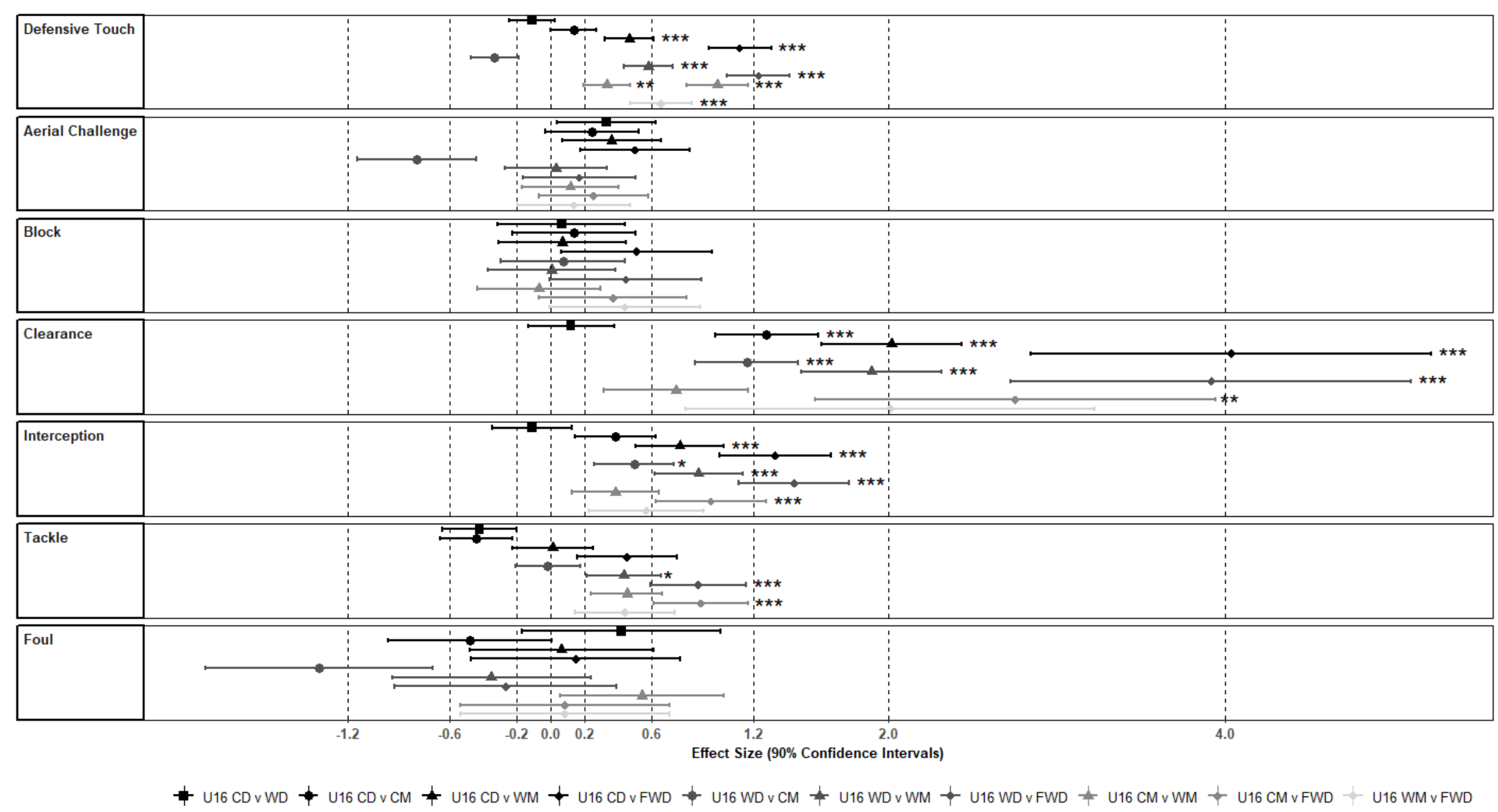

Figure 4. Effect sizes of differences in estimated mean and statistical significance of defensive variables between U16 players by position. *Significant difference $\left(p<0.05^{*}, p<0.01 * *, p<0.001 * * *\right)$ 


\section{Figure captions}

Figure 1. Effect sizes of differences in estimated mean and statistical significance of offensive variables between U14 players by position. *Significant difference ( $p<0.05 *$, $p<0.01 * *, p<0.001 * * *)$

Figure 2. Effect sizes of differences in estimated mean and statistical significance of offensive variables between U16 players by position. *Significant difference $(p<0.05 *$, $p<0.01 * *, p<0.001 * * *)$

Figure 3. Effect sizes of differences in estimated mean and statistical significance of defensive variables between U14 players by position. *Significant difference $(p<0.05 *$, $p<0.01 * *, p<0.001 * * *)$

Figure 4. Effect sizes of differences in estimated mean and statistical significance of defensive variables between U16 players by position. *Significant difference $(p<0.05 *$, $\left.p<0.01^{* *}, p<0.001^{* * *}\right)$ 